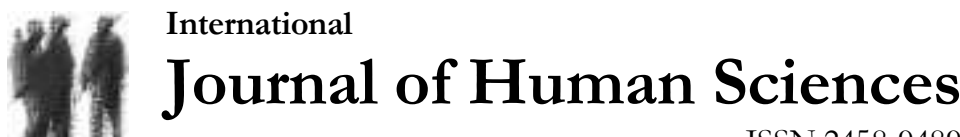 \\ ISSN:2458-9489
}

Volume 17 Issue 1 Year: 2020

\section{Repetitions in art: Campbell's Soup Cans}

\section{Sanatta tekrarlar: Campbell's Çorba Kutuları}

\author{
Figen Girgin $^{1}$
}

\section{Özet}

Sanatta tekrar etme ya da yorumlama çok eskilere dayanmaktadır. Mekanik yolla kopyalamadan çok daha önce tekrarlama çoğunlukla usta-çırak öğretisi ya da gözü eğitme amaciyla gerçekleştirilirken; mekanik yolla kopyalama benzerlerin üretilmesine, dijital yolla kopyalama ise benzerlerin daha fazla dolaşımına ve erişimine olanak sağladi. 20. yüzyıldan itibaren sanat yapıtı daha kolay ulaşılır hale geldi. Dünyanın çeşitli yerlerinde, müze ve galerilerde sergilenen sanat yapitlar1, onlardan kilometrelerce ötede olan başka sanatçılara ya da sanat alıcilarına ulaşabildi ya da yaşam alanlarında karşılarına çıktı. Orijinal, artık kopyalar1 ile birlikte dağılımdaydı. Benzer durum, internet çağındaki günümüzde hem daha hızlı hem de daha yaygındır. Ancak Warhol tüm bunların ötesinde, mekanik kopyalamayı yadsımadan, hali hazırda bir grafik tasarıma sahip ve kopyaları ile birlikte dolaşımda olan bir tüketim nesnesini, sanat dünyasina sokar. Binlerce kopyası olan bir çorba kutusunu tek başına ya da onun kopyaları ile birlikte sergiler. Sanat ve yaşamı iç içe geçirir ya da yaşadığı çağda, kendi toplumundaki popüler kültürtüketim anlayışını reddetmediğini gösterir. Binlerce kopyaya sahip olan çorba kutularının grafik tasarım, Warhol tarafindan tekrarlanarak, onun imzası ile orijinalik kazanmıştır. Onun çorba kutuları resimleri ise hem çağdaşları hem de günümüzdeki sanatçılarca tekrarlanmaktadır. Zaten kopya olan bir asıl, tekrarlandığında aynı

\footnotetext{
1 Araş. Gör. Dr., Eğitim Fakültesi, Güzel Sanatlar Eğitimi Bölümü, Resim-İş Eğitimi Anabilim Dalı, figengirgin@trakya.edu.tr
} 
same effect when it is repeated? How do original, unique, copy, reappear in Campbell's Soup Cans? Why and how has Campbell's Soup Cans been repeated in art? In this research, these questions were tried to be answered through the works of the artists who recreated Campbell's Soup Boxes.

Keywords: Campbell's Soup Cans, Quote, Imitation, Repetition, Contemporary Art. etkiyi verebilir mi? Orijinallik, özgünlük, kopya, tekrar Campbell's Çorba Kutuları'nda ne şekilde ortaya çıkar? Campbell's Çorba Kutuları sanatta niçin ve ne şekilde tekrarlanmıştır? sorularına Warhol'un Campbell's Çorba Kutuları adlı resmi ve bu resmi tekrarlayan sanatçların yapitları üzerinden cevap aranmaya çalışılmıştır.

Anahtar Kelimeler: Campbell's Çorba Kutuları, Yineleme, Taklit, Tekrarlama, Çağdaş Sanat.

(Extended English summary is at the end of this document)

\section{Giriş}

Hazır bir nesnenin sanata taşınması yeni bir olay değildir. Ancak, Andy Warhol'un sanata soktuğu tüketim malzemesi bu süreci farklı kılar. Dönemin çorba kutusu, kopyası ile varlığını ilan eder. Ancak bu ilan ediş, endüstride değil sanatın içindedir. Var edilmişin sanatta yeniden inşası ve yeniden inşa edilmişin yinelenen birçok kopyası. Warhol'da, asıllar ve kopyalar birbirine karışmış durumdadır. Üstelik bu sadece sanatçının kendisi tarafından yinelenmez. Başka sanatçlar da bu tüketim nesnesini yinelemeye devam ederler. Asıl soru şudur? Onların tekrar ettikleri, endüstriyel bir çorba kutusunun grafik tasarımı mı? Yoksa Warhol'un tavrı mıdır? Bir kopya yinelendiğinde asıla dönüşebilir mi? Ya da o zaten kopya olduğunu kabul ettiği için, asıl olmak gibi bir niyeti yok mudur? Daha da arttırlabilecek bu sorular bize, onun yeniden üretim anlayışını farklı bir dönemece soktuğunu düşündürtmektedir.

\section{Campbell's Çorba Kutuları ve Tekrarlar}

Bir nesnenin sanat dünyasına taşınması yeni bir durum değildir. Warhol'dan önce natürmort geleneğinde birçok cansız öğe, bazen kendi olarak bazen ise yüklendikleri sembolik anlamlarla resmedilmiştir. Ancak Danto'nun (2016:167) da ifade ettiği gibi: "Warhol bunları temsili düzleme taşımış, hatta neredeyse yıldızlaştırmış, fakat hiçbir surette natürmortlaştırmamıştır”. Warhol, Campbell's Corba Kutularn'nı resmederken yanına ilave bir öğeye ihtiyaç duymaz. Logosu, üzerindeki yazısı ile yaşadığı dönemde Amerikan toplumunun ilk bakışta tanıyabileceği bir market ürünüdür.

Bu çorba kutusu, Feuerbach'ın "dünyevi hakikati takdis etmek" olarak adlandırdığ1 sadece kendilerini sembolize ettikleri için tüketilen yiyeceklerden biridir. Daha önce kutsanmamış, bir ticari ürün olarak görülen nesne, sanatın merkezinde yerini alır. Çorba kutuları bazen Resim 1'de olduğu gibi tek başına bazen ise aynı kutunun tekrarından oluşan bir dizilime sahiptir. Warhol, Amerikan mutfağına ait olan çorba kutuları, coca cola gibi tüketim ürünlerini eşitlikçi görür. Kişinin zenginliği ya da fakirliğine göre içeriği değişmez. Herkes için her daim aynıdır (Danto, 2016, ss.167-168). O, sıradan bir nesneyi kullanırken sanatın geleneksel yöntemlerini de sorgular. Sanat yapıtının yüceliği ya da basitliği ya da onu sanat eseri yapan şeyin, kullanılan nesne tercihi ile sınırlandırılamayacağını gösterir.

$\mathrm{Bu}$ tüketim nesnelerini resmederken çoğunlukla kullandığı serigrafi, onun çoğaltma ya da benzerlerini üretme tavrı için de oldukça uygun bir tekniktir. "Keşke başkaları da serigrafi yapmaya başlasa, o zaman resimlerimin benim mi yoksa bir başkasının $\mathrm{m} ı$ olduğu anlaşılmazdı" der. Warhol, eserlerini tanımaya ya da onun elinden çıkıp çıkmadığını ayırt etmeye itecek bir duruma ve sanatçının müellif rolünde olmasına da karşıdır (Danto, 2015, s.114). 


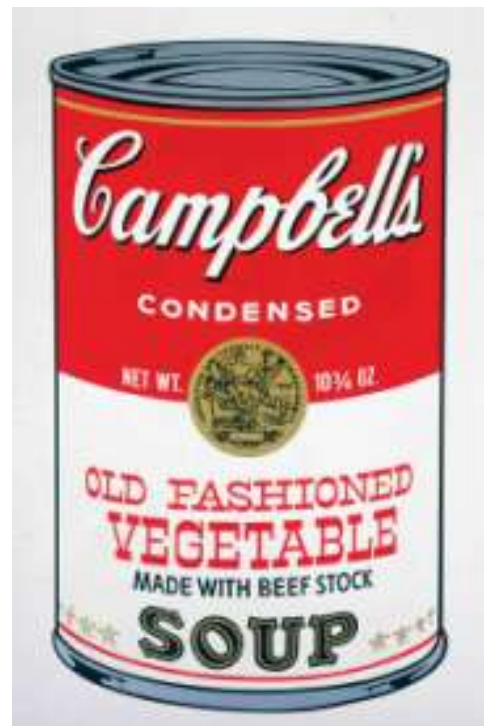

Resim 1. Andy Warhol, Campbell’s Çorba Kutuları II, 1969, Serigrafi baskı, $88.9 \times 58.4 \mathrm{~cm}$

Warhol'un altmıslı yıllarda Campbell's Corba Kutular'nı resmetmesi, simulasyon ve tüm modern sanat için yankılar uyandırmıstır. Ticari nesnenin kutsallaşması. Ancak Baudrillard'a göre 1986'da çorba kutularının resmedilmiş olması yank1 uyandıracak bir şey değildir, sadece simulasyonun basmakalıpları içinde kalır. Altmışlı yıllarda özgün bir tarzla özgünlük kavramına saldırllırken, seksenli yıllarda özgün olmayan, özgün olmayan bir tarzda yeniden üretilmektedir. Altmışlı yllarda ticari ürünün sanata girmesi sanatta dahiyaneliğe, simulasyon dehasina yol açıyor. Seksenlerde ise, reklam dehası ticari ürünün yeni bir evrenini başlatıyor ve resmi sanat, ticari ürünü estetikleştiriyor (Baudrillard, 2000, s.100).

Warhol'un logolanı ile birlikte sunduğu bu ticari ürün, süpermarkete giden, o kültürü yaşayan insanlar için onların tanınmasını sağlıyordu. Öyle ki bu etiketlerden habersiz olmak, meşhur bir aktörün kim olduğunu sormakla eş değer bir yabancilı̆̆n göstergesidir. Di Antonio: "İnsan ne yerse odur. Biz meşrubatız, konserve çorbayız, hamburgeriz, patates cipsiyiz, turşuyuz...Biz Pop'uz, boya değiliz" sözleri ile Warhol'un resmettiği, sanatın aradığı şeyi sunmak için gerçekliğin ürünlerini kullanma yolunu seçmesini oldukça iyi vurgular (Danto, 2016, ss.168-171). Ancak durum, yani tekrar etme eylemi günümüze geldiğinde değişiyor. Çünkü Warhol'un yaşadığı dönemde toplumu için tüketilen ya da aşina olunan nesne, bu çorba kutularını yineleyenlerin kültürü ile bağdaşmıyor veya artık kullanılan bir ürün olmaktan ziyade Warhol'un imgeleri olarak ön planda yer alıyor. Onun yaşadığ dönemde insanlar, kullandıkları bir tüketim nesnesini bir müzede ya da galeride gördüklerinde sanat, onların günlük yaşamlarına indirgenmişti. Sanat dünyası ile ortak kültür iç içe geçmişti. Ancak, ondan sonra yapılan bu Campbell's Çorba Kutulari'nı gören izleyicinin zihnindeki imge, önce Warhol olacaktır. Bu anlamda Warhol'un yinelemeye başka bir boyut kazandırdığını söyleyebiliriz. Çünkü bir taklit ya da esinlenmiş bir yapıt aslı biliniyorsa elbette önce onu hatırlatır. Bunu Son Akşam Yemeği, Mona Lisa, İnci Küpeli Kız gibi birçok yapıtta görürüz. Bu yapıtların yinelemeleri, benzer bir kompozisyona sahipse, akla ilk önce o yapttlar gelir. Bunlar sanatçlara ait orijinal ve özgün eserlerdir. Oysa Warhol'un resmettiği çorba kutuları, orijinal olmalarına karşın özgünlügü tüketim markalarının ambalajlarının taklitleri olarak sunulması ile sarsılır. Buna karşın kendi döneminin izleyicisi için bu eser, Campbell's çorba kutularının bir kopyası iken şimdi tekrar sanat dünyasında yer alan bu çorba kutuları, şimdinin izleyicisinin zihninde Warhol'un çorba kutularının esinlenmeleridir. Oysa bir Mona Lisa resminden ister Leonardo da Vinci zamanında isterse günümüzde esinlenilmiş ya da taklidi yapılmış olsun, o hem Da Vinci'nin yaşadığı dönemde hem de günümüzdeki izleyici için kaynağı $\mathrm{Da}$ Vinci olan bir yineleme olarak kalacaktır. Bu anlamda bir tüketim nesnesinin sanat dünyasına, onun logosuna rağmen kendi sanatçı kimliği ile 
kazandırması, değerini marketten sanat piyasasına kaydırarak yüceltmesi bakımından Warhol oldukça başarılıdır.

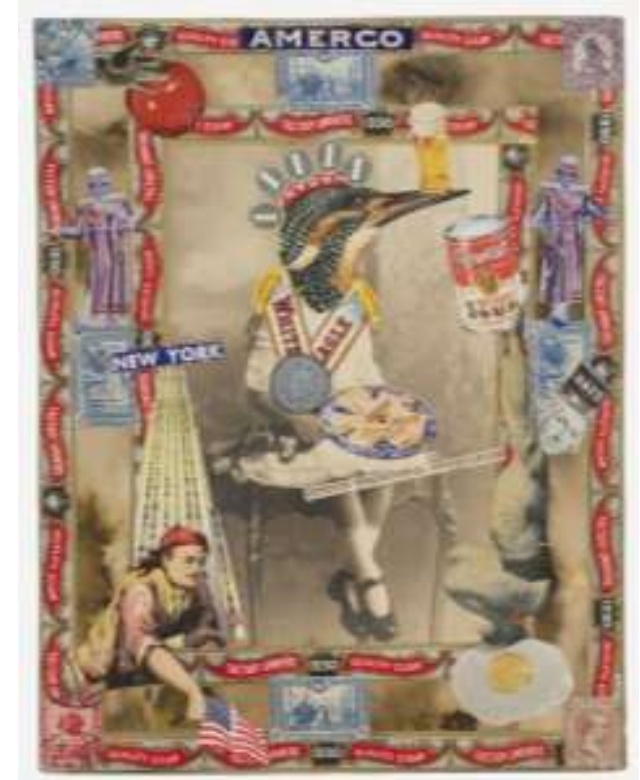

Resim 2. Felipe Jesús Consalvos, Meraklı Geleneksel Gözlemler, 1920-50, Kağıt üzerine kolaj, 24.1x19.1 cm

Warhol'dan çok daha önce Campbell's Corba Kutular'nı resmeden biri vardır. O da Felipe Jesus Consalvos'dur. 1920'lerde Havana'dan Miami'ye göç eden bir sigara sarıcısı olan Consalvos, etrafindaki her şeyi kolaja dönüştürebilen biridir. Sigara kutuları, pullar, buluntu fotoğraflar, eski aile portreleri, müzik aletleri ve mobilyalar. Sigara bantları ve kutularından aldığı simetri kendi içinde sanatsal pratikler olarak onun çalışmalarının anahtar öğesidir. Merakh Geleneksel Gözlemler'de (Resim 2) onun bu yaklaşımı oldukça net olarak görülebilir. Hem resmin en dış hattında hem de ondan biraz daha içeride adeta çerçeve gibi sigara bantları kullanılmıştır. Ancak burada çerçeve görüntüsü veren simetri, çorba kutusu, yumurta, sporcu, çok katlı bir yap1 gibi öğelerle kesintiye uğrar. Bu kadar saçma ya da birbiriyle alakasız öğelerin bir arada kullanılması çağdaş sosyo-politik değerlerin eleştirisinde çok yönlülüğe sahiptir. Dadaizm'in estetiğinde yer alan ve Avrupa'da eş zamanlı olarak gerçekleşen değerlerle benzerlik söz konusu. Buna rağmen, Consalvos'un Avrupalı çağdaşlarını bildiğine dair herhangi bir kanıt yok. Çoğunlukla İngilizce olarak seçilmiş metin yazıları, tarihsel figürlerle iç içedir. Hitler ve George Washington gibi kişilerin kolajlarında yer alması, onun kolajın politik tarafinın ilk örnekleri arasında yer almasını sağlar. Kurt Schwitters ve Max Ernst gibi Dadacıların sosyo-politik hicvini ve saçma dürtülerini paylaşmakta. Hayatı boyunca tanınmayan ve hakkında çok az şey bilinen bir sanatçıdır. Consalvos etrafinda değişen dünyayı geri dönüştüren ve canlandıran biriydi (Jansen, 2013). Bu açıdan bakıldığında Warhol'un tavrı ile bir benzerlik söz konusu. Consalvos da tupk1 Warhol gibi yaşadığ dönemin kültürel, sosyal, politik ve tüketim öğelerini sanat dünyasına taşımayı seçmiştir. Ancak çorba kutusu, etiketi ile birlikte yer almasına karşın, onun resminde bütünün parçalarından biri olarak yer alır. Warhol'da ise çorba kutusu başlı başınadır. Yanında başka bir öğe olacaksa o da yine kendi kopyasıdır. Aynı nesne hatta fabrikasyon üretimindeki hali ile eşdeğer sunulsa bile nesneyi yüceleştirme durumu Consalvos'da söz konusu değildir. 
Resim 3. Richard Pettibone, Campbell's Çorba Kutusu, Sebze ve Arpalı Sığır Eti, Tuval üzerine akrilik ve serigrafi boyası, Peder Bonnier Inc, New York

Özel Koleksiyon, İsveç

Warhol'un kendi kültürü için tanıdık olan imajları sanatta kullanma tavrını Richard Pettibone sanat eserleri üzerinde gerçekleştirir. 60'lı yıllardan itibaren diğer sanatçların eserlerinin küçük boyutlu çalışmalarını yapar. Ve bu boyuttaki işlerini de "Benim için kocaman" diye niteler. "Illk Warhol taklidini yaptığım zaman, 1960'ların sonlarında genç bir sanatçıydım. Harika bir ressam olmak istedim. Bunun, harika bir tabloyu kopyalamaktan daha iyi bir yolu var mi? " (Walsh, 2011). Warhol çorba kutularını basit grafiksel bir şema olmaktan çıkarıp, sanat mecrasında yüceleştirmeyi seçerken; Pettibone, kendi ressamlığını yüceleştirmek için bilinen ve resmedilmiş bir yapıtı kopyalamayı seçerek yapar.

Sanatçı, özgünlük sorunsalını, kopyanın boyut konusundaki özgürlüğü ile birleştirerek yapıtları küçük ebatlı olarak kopyalar. Onların bütünlügünü bozmadan sevimli birer işe dönüştürür. Hayranlı̆̆1 özellikle Warhol'un eserlerinedir. 1965'te New York'a yaptuğı bir gezide Warhol'u arayarak kendisi ile görüşme isteğini ifade eder. Warhol, kendi yapıtlarının sahiplenilmiş olduğunu görünce, bu kopyaları komik olarak niteler. Pettibone'a göre ise hâlihazırda kopyalamakta olan bir sanatçının işlerinin neden kopyası yapılmasındı ki? $\mathrm{O}$, Warhol'un yapıtlarını kendine mâl etmek için değil yeniden üretmek ve keşfetmek için kopyalamayı yeğler (Leo Castelli Gallery, 2004). 


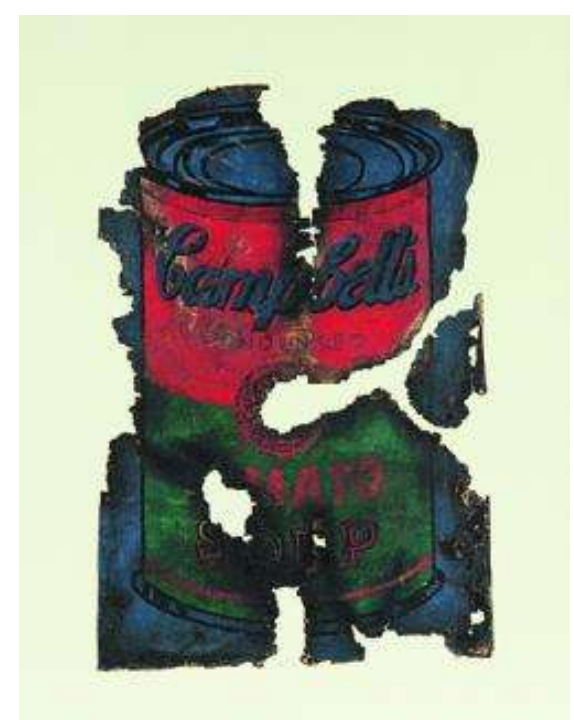

Resim 4. Vitaly Komar ve Alexander Melamid,, Post-Art \#1 (A. Warhol), 1973, Tuval üzerine yağlıboya, $60 \times 60 \mathrm{~cm}$

Pettibone’un yaptığının aksine, benzerliğin daha aza indirgendiği bu eser (Resim 4), Vitaly Komar ve Alexander Melamid'e ait. Birlikte çalışan bu sanatçlar, Geleceğin Resimleri (Pictures of the Future) serisinde Post-Art temalı yaptıkları resimlerde, Warhol, Lichtenstein, Jasper Johns, Indiana gibi sanatçılara göndermede bulunurlar. Onların Amerikalı sanatçlar ve Amerikan Pop-Art'ı ile teorik anlamda sanatsal ilişkileri ideoloji çerçevesindedir. Warhol'un sanatında, tüketim mallarının aşırılığına dikkat çeken anlayışa benzer teorik sanatsal yaklaşım bu iki sanatçıda Sovyet Birliği’ndeki ideolojinin aşırılığına dikkat çekmek için kullanılır. Amerika'da reklam unsuru olan bu işlerin her bir parçası, Sovyet toplumunda yaygın olan Sovyet propagandası ile ilişkilidir (Vitaly Komar and..., tarihsiz).

Komar ve Melamid için resmin kompozisyonu ve rengi kadar hikâyesi de önemlidir ve resmi etkileyici kılan unsurlardan biridir. Onlar tarihte yer etmiş görüntülere yeni bir görüş eklerler. Çok üsluplu görüntülerin birleşimi, eklektik kompozisyonlar onların 'Post-Art' olarak adlandırdıkları işlerinin genel çerçevesini oluşturur. Pop-Art'ı analiz ettiklerinde, Pop-Art'in çoğaltılabilen bu başyapıtlarının çok pahalı ve tanınmış olduğunu görürler. Aynı zamanda bu işler, tanınmış müzelerde de yer alır. Sanatın seyrini değiştiren bu işler, bir Da Vinci ya da Rembrandt kadar klasik değildir. Bunun nedeni olarak da akımın hala çok genç olması ve geçmişinin çok eskiye dayanmaması gösterilir. Belki bir 200 yll sonra bu yapitlar ve sanatçllar klasikleşeceklerdir. Ancak bu iki sanatçı 200 yıl beklemenin çok uzun bir süre olacağı düşüncesi ile bu çalş̧malara bir şeyler eklerlerse, onların şimdi klasik olmalarını sağlayabilecekleri görüşüyle yola çıkarlar (Feldman Gallery, tarihsiz). Bunun sonucu olarak da Post-Art \#1 'deki gibi çorba kutularının kopyalarına büyük yanıklarla delikler açarak, bu çalışmaların geçmişlerine ve hikâyelerine kendilerince bir katkı sağlarlar. $\mathrm{Bu}$ yakma işlemi yeni olanı eskitme, tarihin derinliklerinden çıkarma gibi bir anlama bürünür.

Bu iki sanatçının Warhol ile ilişkisi çorba kutuları ile sınırlı kalmaz. Onunla kurdukları ilişkiyi o kadar ileri götürürler ki gerçekleştirdikleri bir eylemde onun ruhunu bile satarlar. ${ }^{2}$ Sovyet kültürü, ideolojinin yanı sıra, Warhol ve Amerikan yaşamının politik, dini, sosyal temaları onlar için inceleme konusudur ve Amerikan sanatını alaycı satirik bir dille yeniden yorumlarlar.

\footnotetext{
2 1970’lerde insan ruhlarını satın almak ve satma projesi için bir şirket kurarlar ve Warhol gibi birkaç kişinin ruhlarını satın alırlar. Sonra 19 Mayıs 1979'da saat:12.00'de Sovyetler Birliği ile aynı zamanda Moskova ve New York'ta 'Resmi Olmayan Amerikan Sanatı'nın İlk Açık Arttırması' reklamını New York Times’te verirler. Hararetli geçen açı arttırma Mikhail Odnoralov'un dairesinde gerçekleşir ve Warhol'un ruhu 30 rubleye satılır (Kalinsky, tarihsiz).
} 


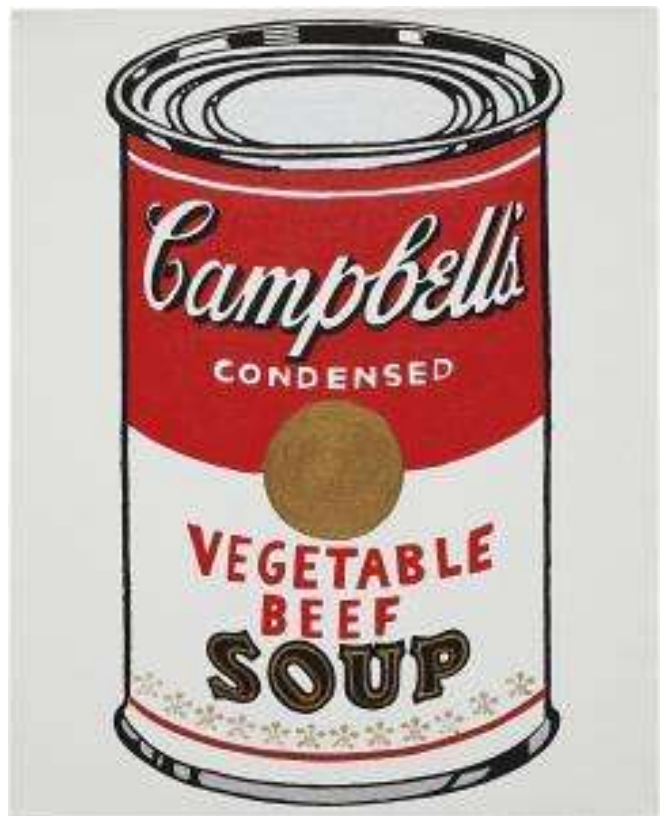

Resim 5. Mike Bidlo, Warhol Değil (Campbell's Çorba Kutusu, Tavuklu Bamya

Çorbası, 1984-86, Tuval üzerine serigrafi ve akrilik boya, $51 \times 41 \mathrm{~cm}$

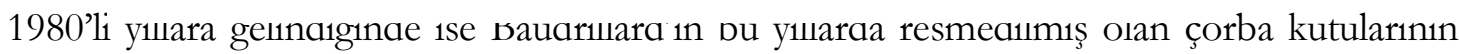
yankı uyandıracak bir şey olmadığını söylediği bir eser ile karşılaşıyoruz. Mike Bidlo’nun ticari bir ürünü kopyalayan Warhol'un tekrarı ile karşımıza çıkmasının altında yatan sebep kanımca ticari bir ürünü estetikleştirmek değildir. Bidlo'nun, Warhol'un sanatta fabrikasyon tavrını, orijinallik ve özgünlük bağlamında yeniden ele aldığı söylenebilir. Warhol, grafiksel ambalajı ile ticari bir ürünü kendi piyasasından, sanat dünyasına kaydırmıştı. Bir tüketim ürününü kopyalamıştı. Bidlo ise sanat dünyasına kaymış çorba kutularını kendi imzası ile tekrar gün yüzüne çıkarır. Sanatçının kimliği ve orijinal yapıt kavramını sorgulayarak derin bir kriz yaratır. Sanatçı, gönderme yaptığ1 çoğu yapıtın ya da sanatçısının adını kendi resminin başlığına -değil/dir- kelimesini ekleyerek sunar ve izleyiciyi şaşırtır. Birçok sanatçıya ait eseri bu olumsuzlama başlığı ile adlandırır. Olumsuzlama ile isimlendirdiği bu kopyaların temelinde orijinallik ve özgünlük kavramlarının sorgulanması yatar. Warhol'un günlük hayatın içinde olan her şeyin sanata mâl edilebileceğini haykırırcasına yaptıklarını, Bidlo sanatta var olan her şeyin, ya da bir sanatçı elinden çıkmış her eserin başka bir sanatçının kopyalamasına açık olduğunu gösterir. 


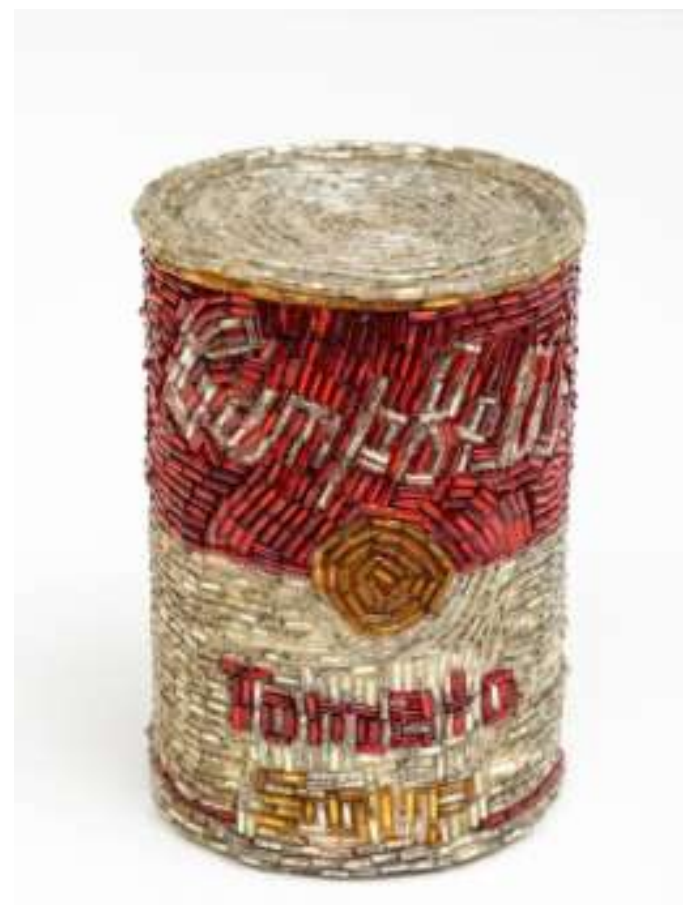

Resim 6. Liza Lou, Campbell's Çorbası, Domates, 1992, Kağıt mache ve cam boncuklar, $10.5 \times 6.7 \mathrm{~cm}$

Liza Lou ise, üç boyutluluktan iki boyuta indirgenen Campbell's çorba kutularını tekrar özüne döndürür. Çorba kutusunun logusuna ve kendi rengine denk parlak renkli boncuklarla onu üç boyutlu olarak yorumlar. Warhol'un referans olarak alındığ1, Campbell's çorba kutularının aralarında yer aldığı 1991-95 yılları arasında dört yıl gibi uzun bir süreçte gerçekleştirilen 'Mutfak' adlı enstalasyonda yer alan her bir öğeyi boncukla kaplamak ya da oluşturmak için kürdanla tutkal kullanmış ve boncukları da cımbızla yerleştirmiştir. Bu enstalasyonda her bir öğe, tabak, bardak, buzdolabındaki yiyecekler boncuklarla kaplanmıştır. Hatta musluktan akan su bile mavi boncuklarla yapilmıştır. Lou, Pop-Sanat'ın tüketim ürünlerini sanata taşıma durumunu emek ile yoğurur ve "Pop-Sanat'1 yavaşlatma fikrini sevdim," der (Solti, tarihsiz). Lou, Pop-Sanat'in seri üretimi destekleme veya izleyicinin önüne kendi gerçekliği olarak sunma tavrını ve kısa sürede çoğaltma eylemini uzun bir zamana yayar. Yine Warhol'un daha fazla ya da daha hızlı üretmesine olanak sağlayan serigrafinin karşısına da daha fazla insan gücü ve emekle çıkar. Aslında onun burada PopSanat'ı yavaşlatmasını sağlayan şey daha çok, kullandığı malzeme ve tekniğidir.

Lou'nun çoğu zaman amacı mütevazı bir şeyi yüceltmek veya çirkin bir şeyi güzelleştirmek üzerinedir. Sanat tarihçisi ve eleştirmen Robert Pincus-Witten'e göre o ,Pop-Sanat, feminizm ve kavramsalcılıktan ortaya çıkan konuların eşsiz bir sentezini sunar. Sanatçı, bir boncuk dükkânına girdiğinde, boyadan daha ilginç olan bu malzeme ile tanışır. İlk olarak soyut resimlerine bu malzemeyi eklemeye başladığında, hem öğretmenleri hem de sınıf arkadaşlarının onu incittiğini ifade eder. "Gerçekten yaptı̆̆ım şeyden nefret ettim... Ancak bu malzemenin insanları ne kadar altüst ettiğini gördüğümde, bunun iyi bir şey olduğu çok açıtu,” (Bagley, 2008) sözleri ile bu malzemeyi kullanma konusundaki kararlığını dile getirir.

Lou'nun cam boncuklarla çalıştı̆ı bu işleri başta bir ambalajlama olarak görülebilir. Ancak zamanla onlar, emek gücünün çok fazla olduğu ve biçimsel olarak kavramsal türde olan heykellere dönüşmüştür. Boncuklarla oluşturduğu, bardak, tabak, kahve fincanı, çikolata, çorba kutusu gibi işlerinde el emeğinin gerçek değerini vurgular. "En çok tekrar eden, zemini ovalamak gibi zorlu iş 
türü bile değere de sahiptir. Bu yüzden emeğe ve gündelik yaşama yücelik katmayı umuyorum,” (Solti, tarihsiz) sözleri onun emeği ne kadar önemsediğini gösterir.

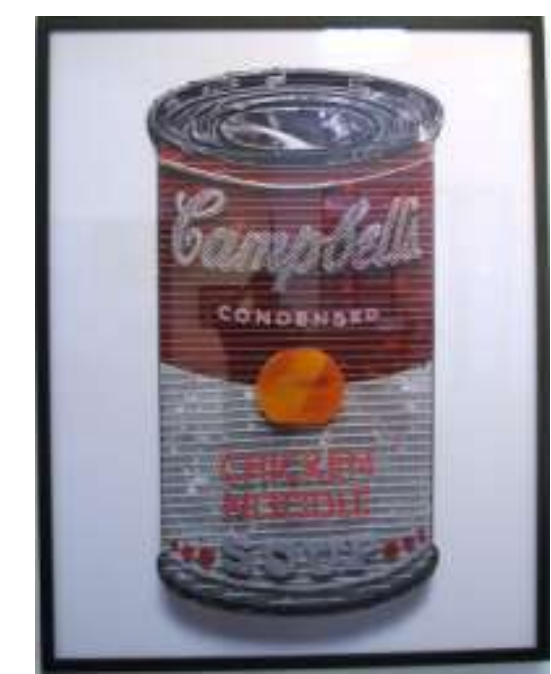

Resim 7. Vik Muniz, Radyatör Tavuk Erişte (Warhol'dan Sonra), 2007, Kromojenik bask1, 200,5x 157,5 cm (çerçeveli)

21.yüzyıla gelindiğinde Campbell's Çorba Kutularinın hâlâ sanatçılarca yinelendiğini görüyoruz. Bu sanatçilardan biri de Vik Muniz'dir. Muniz; Corot, Courbet, Monet, Da Vinci, Caravaggio, Rothko, Moris gibi sanatçılara ait eserleri kendi tarzında yeniden üretir. "Kültürler, ritüeller ve davranış kalıplarının içten bir şekilde iletilmesine dayanır. Hücreden hücreyi, kelimeden kelimeyi, görüntüden görüntüyü kopyalamak dünyamızı bilinen hale getirmektir”. Bu, 60’lardaki Pop hareketinin belki de bir mirasıdır. Ünlü kişilerin, bira kutularının, çorba kutularının resmedilmesi ya da yeniden tasarımlanması Muniz'in mizah anlayışı ile benzerlik taşır. Makineler bize çoğaltma imkânı tanıdı. Kopyalamak onların sayesinde daha da kolaylaştı. Kuşkusuz hem kullandığı serigrafi tekniği hem de sanata bakış açısı ile Warhol bunu en etkin kullananlardandı. Muniz, kopyalamayı sadece bir yeniden okuma veya görüntünün kompozisyonunu hedef alan bir sürecin anlayışı olarak geliştirmez. Mükemmel kopyalar elde etmek için uğraşmaz (Amaral, 2001). Geçmiş, Muniz'in mizah dili ile yinelenir, tazelenir.

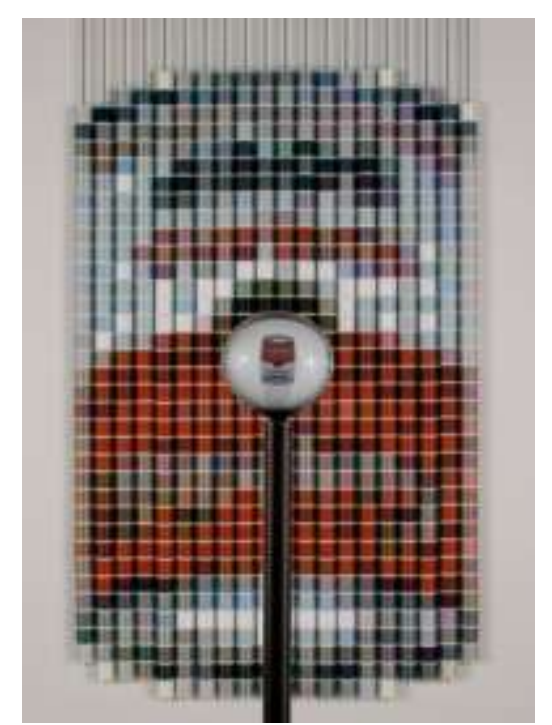

Resim 8. Devorah Sperber, Warhol'dan Sonra, 2008, 698 iplik makarası, paslanmaz çelik bilyeli zincir, asma aparatı, metal stant, akrilik şeffaf akrilik küre, $114.3 \times 63.5 \mathrm{~cm}$ 
Devorah Sperber ise sanatın birçok dönemi ile sorgulama içine giren ve birçok sanat yapıtını yorumlayan biridir. Sanat eserlerini renkli iplik makaraları ile oluşturur ve yaptı̆̆ bu dizilimin önüne akrilik bir küre yerleştirir. Warbol'dan Sonra (Resim 8) adlı bu yapıt, 698 adet iplik makarası ve bir akrilik küreden oluşur. İlk bakışta rastgele dizilmiş izlenimi uyandıran iplik makaraları, görüntüyü $180^{\circ}$ çeviren akrilik küre sayesinde, aslında bu rastgele izlenimi veren makaraların bilinçli bir dizilimde olduklarını ispat eder. Bir görüntüyü büyüttüğümüzde, varllğ1 silikleşir ve biz onun piksellerini görmeye başlarız. Her bir piksel kendi rengine bürünür. Sperber'in işleri de aynen böyledir. Onun pikselleri, iplik makaralarıdır. Yakından bakıldı̆̆ında sadece iplik makaralarını renk ve biçimi baskın olarak gören göz, uzaklaştıkça bu makaraları renk olarak algılamaya ve makaraların biçiminden çok, onların oluşturduğu bütüne asıl görüntüye ulaşmaya başlar. İzleyici akrilik küreden baktığında ise ters duran bu görüntü düzleşir ve daha net hale gelir. Burada, çorba kutularını tekrarlarken Sperber'in amacı ne ticari bir ürünü estetik hale getirmek ne de Campbell's Corba Kutular'nı kopyalamaktır. Warhol, burada onun geçmişi şimdiye kendi tekniği ile getirmek, güncellemek adına seçtiği ve belki de sayg1 da duyduğu sanatçlardan biridir. Sperber'de de tıpk1 Lou'da olduğu gibi çorba kutularının bu yeniden üretilmiş hali, fazlasıyla emek gerektirir.

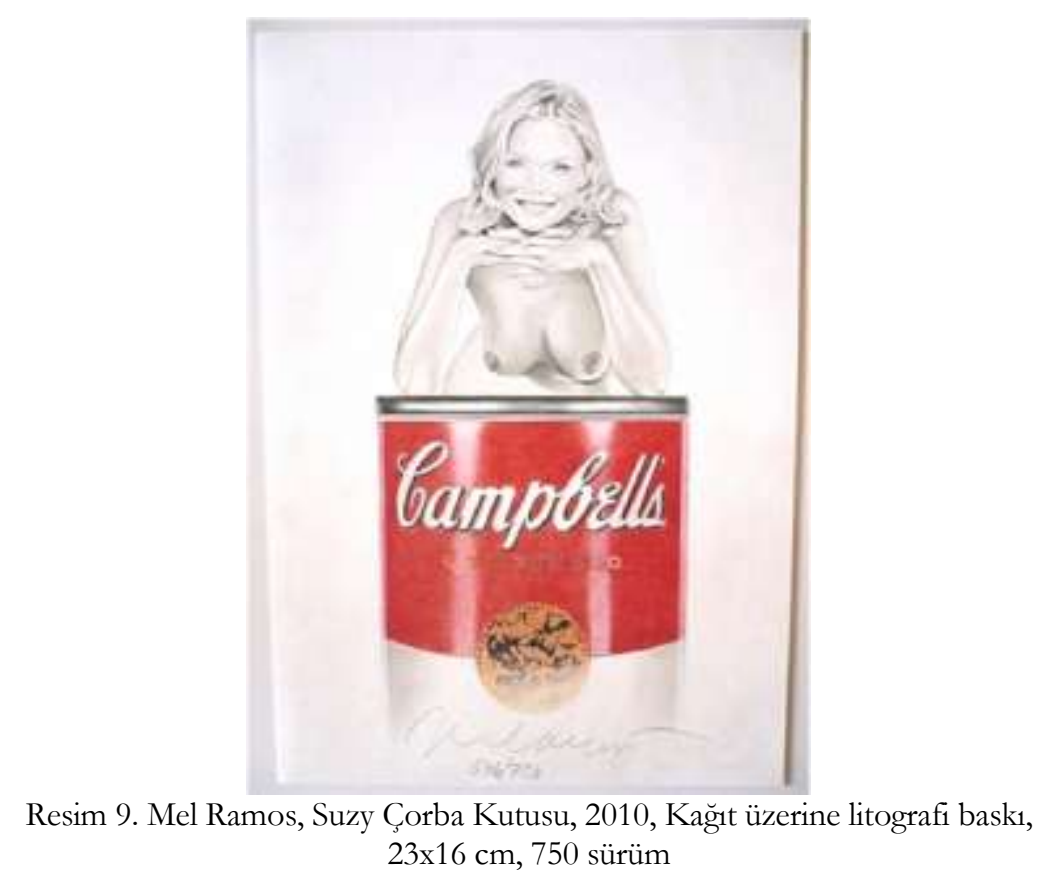

Şu ana kadar Warhol'a benzer bir anlayışla, ondan sonra yorumlanan çorba kutularının hep tek başına olduğu görülmüştü. Ancak Susy Çorba Kutusu (Resim 9) adlı resimde çorba kutusu, dirseklerini onun üzerine koymuş çıplak bir kadınla gösterilir. Mel Ramos, Campbell's çorba kutusu ile çıplak bir kadını birleştirerek yaptığ bu resim ile tüketim kültürüne ve reklam endüstrisine değinir. Sıklıkla medya ve reklam unsuru olarak kadın bedeninin kullanılması ve tüketim nesnesi ile ilişkilendirilmesi, popüler kültürün yöntemlerinden biridir. $\mathrm{O}$ da, Campbell's çorba kutularını tanıtmak için seçtĭgi kadını, çorba kutusuna dayanmış olarak gösterir. Campbell's markasının dışında kalan her şey siyah-beyazdır. Bu, markaların tanıtımları için reklamlarda, afişlerde, tasarımlarda seçilen odak noktası ve ilişkilendirme anlayışına oldukça uygun bir resimdir. 


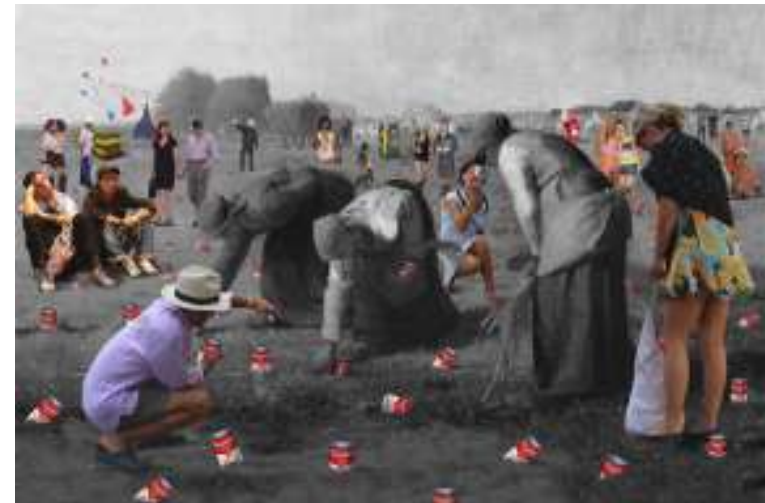

Resim 10. Lluis Barba, Sanatta Turistler, Jean-François Millet 2009, Diasec bask1, 150x200 cm

Değişik dönemlerden, ülkelerden insanları turist olarak tanınmış yapıtların içine yerleştiren Lluis Barba, Sanatta Turistler'de (Resim 10), hem Warhol'a hem de Millet'ye göndermede bulunur. Başak tarlasının her yerine savrulan Campbell's çorba kutuları ve bir tarafta poşete bu kutuları toplayan bir kadın, diğer tarafta ise Millet'nin resmindeki köylü kadınlar. Üretim ve tüketim ilişkisinin esprili bir dille değerlendirildiği bu resimde, eskiye ait olan -Millet-Başak Toplayanlarsiyah-beyaz, günümüze daha yakın olan -Warhol-Campbells Çorba Kutular1- ve turistler ise renklidir. İzleyici, hem geçmişi meraklı gözlerle izleyen pasif konumda hem de yapıtın içine dahil olan aktif konumdadır. Barba'nın bu işi, Warhol'un çorba kutularına ironik ve esprili bir yorumda da bulunur. Çalışmada çorba kutuları iki farklı okuma içerir. Birinci okumada; çorba kutularını basit bir fabrikasyon ürünü ve çöpe dönüşebilen bir nesne olarak görme söz konusuyken ikinci okumada; çorba kutularını tarladaki bir ürün kadar değerli görme ki aynı zamanda bir başyapıta dahil ederek değerini arttırma söz konusudur. Aslında, bir teneke kutunun Warhol'un elinde nasıl sanata dönüşebildiğinin eğlenceli bir yorumu. Millet için tarladaki başak, köylüler ve gerçekleştirdikleri bu iş ne kadar değerliyse Warhol için de tüketim kültürü ve Campbell's çorba kutuları o kadar değerlidir.

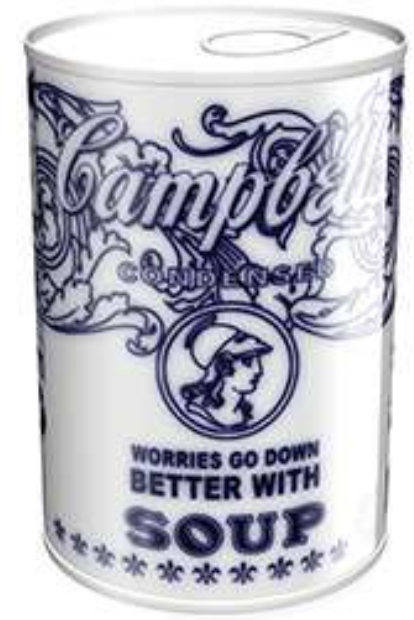

Resim 11. Magnus Gjoen, Çorba İle İlgili Endişeleri Daha İyi Hale Getirmek, 2012, Giclée bask1, 40x40 cm, 100 sürüm

Teneke bir kutuyu seramik hale getirmek onu daha değerli kılar m1 ya da tüketim nesnesi olduğu fikrinden uzaklaştırır mı? Ya da Magnus Gjoen'in eserine verdiği isim gibi Corba ile ilgili endiseleri daha iyi hale getirebilir mi? (Worries Go down Better with Soup) Asıl soru, çorba kutularının sanata taşınması endişesi mi yoksa Warhol'un onu sanatsal bakış açısı ile yorumlama biçimindeki 
endişeyi mi iyileştirmektir? Aslında, çorba kutularının sanat içerisinde bu denli var olması ve hâlâ birilerinin sanat eseri olup olmadığını sorgulaması ve olup olmadığına dair duydukları endişe. Peki, teneke kutu üzerindeki markanın seramiğe taşınması bu endişeyi daha az duyulur hale getirir mi? Bilinen bir gerçek var ki, hangi malzemeyi kullanırsak kullanalım, hangi yüzeye Campbell's yazısını yazarsak yazalım, bu onun bir çorba markası olduğu gerçeğini değiştirmeyecektir. Warhol da zaten bu gerçeği değiştirmek değil, belirgin kılmak istemişti.

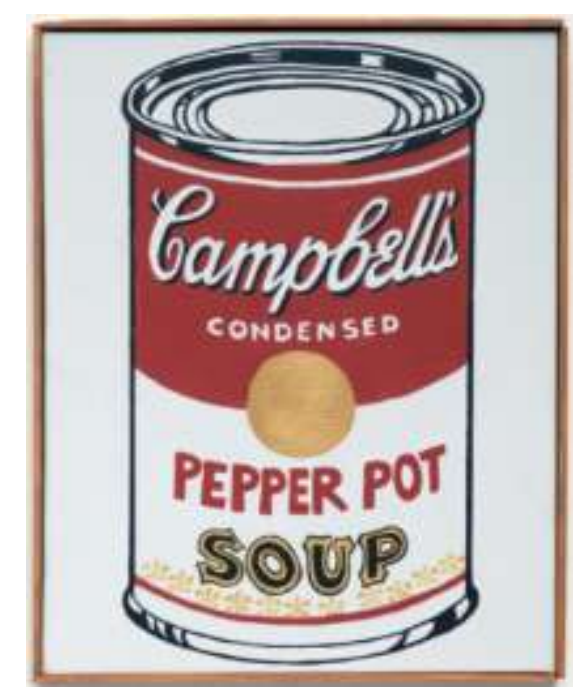

Resim 12. Gregg Gibbs, Andy Warhol Değil, Biberlik, 2013, Tuval üzerine akrilik boya, $50.8 \times 40.6 \mathrm{~cm}$

Gregg Gibbs, Pettibone ve Bidlo'nun tavrına benzer bir yorum ile karşımıza çıkmakta. Pettibone gibi küçük boyutlu çalş̧maz belki ama kopyalama tavrı oldukça benzer. Yine Bidlo'nun değil/değildir olumsuzlamasını o da resminin başlı̆̆ına taşıyarak yapılmış olanın yapılmışlarını oyuncul bir dille adeta yapılacak başka bir şey kalmamış dercesine yineler. Gibbs, büyük çoğunlukla, 20.yüzyll sanatçlarının eserlerini yinelemeyi seçer. Çok daha öncelere gitmeyi tercih etmez.

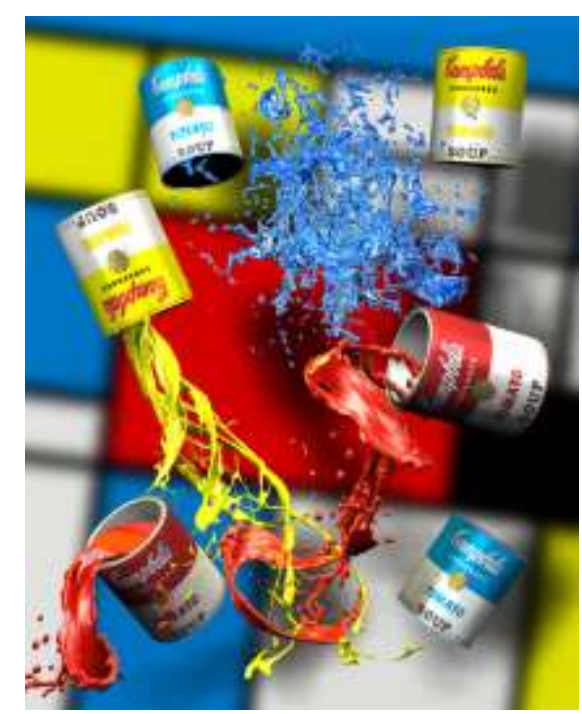

Resim 13. Dominique Mulhem, Campbell's Mondrian, 2018, Bask1, 50x40x2 cm

Dominique Mulhem ise çorba kutularını, boya kutularına dönüştürür ve bir hologram resmi olarak yineler. 1979'da ilk hologram resmini icat eden ilk multimedya sanatçısı olarak bilinmektedir. Mulhem'in ilk hologram resmi, geleneksel yağlıboya resmi ve yüksek teknikteki hologram arasındaki 
bölgede yer alır. Resimleri Pop kültürü ve sanatın sahiplenilmesine yöneliktir. 70’lerin başında farklı 3D teknikleri ile çalışmıştır. Son derece temsili bir formun ötesinde resmi esasen kavramsaldır (Gallery Saint Martin, tarihsiz).

Sanat eserini Campbell's Mondrian'da (Resim 13) olduğu gibi mekân ve zamanda bir hareket sonsuzluğuna sokar. Geçmişle bağı onun 'Sanatçı Portreleri'nde ve 90'lı yıllarda yaptı̆̆ 'Hayali Müze' serisinde karşımıza çıkar. Eserde boya kutularına dönüşen çorba kutuları, dinamik bir görünümdedir. Bu kutulardan dökülen sıçrayan renkler, Mondrian'ın resimlerinde vazgeçilmez olan üç ana rengi taşır. Yine Mondrian'ın bir resmi bu havada asılı olan boya kutularına flu görünümü ile fon olarak hizmet eder. Mondrian'ın imgede yaptığı arındırmayı, Warhol bir adım daha ileri götürür. İzleyicinin karşısına direkt olarak gerçekliği koyar. Mulhem ise, bu iki sanatçıyı dinamik bir kompozisyonda bir araya getirerek hem Warhol'a hem de Mondrian'a atıfta bulunmuş olur.

\section{Sonuç}

Warhol insanları tükettikleri ve eserler üzerinde uzlaştırır ya da bu hayat tarzını inkâr etmediğini izleyiciye gösterir. Çorba kutularını tekrar eden sanatçıların bu anlamda onların ait oldukları yaşam tarzının, kültürünün görüşlerini de konu edindiklerini söyleyebiliriz. Warhol'un logosu ile birlikte kullandığı ticari nesne, izleyici için oldukça tanıdıktır. Logo burada sanat izleyicisi ile tüketici kitleyi aynı platformda buluşturuyor. Oysa günümüzde yapılan çorba kutuları, logoları ile birlikte sunulsalar bile, artkk o logonun önüne geçen bir sanatçı kimliği söz konusu. Warhol Amerikan kültürünün tüketim tercihlerini adeta resimsel olarak belgelemiştir. Çorba kutuları, coca cola şişeleri, Marilyn Monroe, Elvis Presley gibi tanınmış kişiler. O dönemdeki izleyici için bunlar yaşamın bir parçası iken belki şu an olmasa bile bir yüzyll sonrasının izleyicisi için belgeleyici bir yönü ile de devreye girebilecektir. Ondan sonra yapılan yinelemelere baktığımızda Warhol'unki gibi bir anlayış söz konusu değildir. Ancak, Warhol'u yineleyen sanatçıların hiçbirinin kandırmaca gibi bir gayesi de söz konusu değildir. Batı sanatında birbirinin ardı sıra gelen akımlar sayesinde Danto'nun da ifade ettiği gibi (2016:115) “geçmişe etkili” bir bakış açısıyla yaklaşmak mümkündü. Sadece değer değil, yap1 ve anlam kavramları da yeni kimlikler kazanmıştı. Bu değişim 20.yüzyıla gelindiğinde daha hızlı olmaya başlar. Sanatçı, sanatsal şimdinin yanı sıra geçmişi de yeniden yaratmış oluyordu. Bu bağlamda, selefi olan sanatçı Warhol onların çağdaşı oluveriyordu. Sanatın sabit bir kimliği olamayacağı ve herhangi bir şeyin sanat eseri olabileceği inancının arttı̆̆ çağda, yinelemeler daha belirgin hale gelir.

Platon, taklit ettiğimiz kişilere veya şeylere dönüştüğümüzü ve bu sebeple de insanın ahlaka uygun örnekler edinmesi gerektiğini ifade eder. Örneğin Çin sanatında Ni Tsan bir efsane hatta buyruk haline gelmiştir. Saflık, cesaret ve zorluk karşısında sükûnet gibi yüce faziletleri üzerinde toplamıştır. Ni Tsan'ı taklit eden ressam, aynı zamanda ahlaki bir tutum sergilemiş olur ve yücelik olgusunun kendisi haline gelir (Danto, 2016, ss.148-149). Belki benzer bir durumu Campbell's Çorba Kutularinı yineleyen sanatçlar için de söyleyebiliriz. Warhol'un tüketilip kenara atılacak bir teneke kutuyu sanat öğesi haline getirip bunu yine bu tüketim nesnesinin kendisine koşut defalarca kopyalaması, sanat dünyasının geleneksel öğretilerine karşı sergilediği tutum ve tavrı ile yinelenmek için seçilmiş olması muhtemeldir. Geçmişe ait bir eser farklı gerekçelerle günümüzde yeniden var edilir. Şimdinin dili ile güncellenir. Bazen eserin teması (Guernica'daki savaş teması gibi) yakın dönemimizdeki bir savaş ya da katliam ile ilişkilendirilir. Yeni yapıt, geçmiştekini çağrıştırır ama aynı zamanda izleyici için şimdiye ait tarihsel bir ana da vurguda bulunur. Oysa burada sanatçların etkilendikleri eser ticari bir ürünün kopyasıdır. Warhol'un yaşadığı dönemde, popüler kültür ve tüketim ile bağ kurduğu sanatsal anlayışı, 21.yy'da bile yinelenir durumdadır. Ancak, onun yüceltici tavırdaki Campbell's çorba kutuları, sonrasındaki yinelemelerde her zaman bu bakış açısında olmamıştır. Warhol, çorba kutularını, Brillo kutularını sanata ilk soktuğunda popüler imge, sanatın içine dahil olmuş ve tüketim, sanat eserine dönüşmüştü. Bu o dönemde çığır açan bir yenilikti. Warhol'un kutsallaştırdığı ticari nesne tekrar kutsallaşabilir mi? Ya da 21.yüzyılda yinelendiğinde yaşamın-sanatla iç içe geçmesindeki etkiyi izleyiciye verebilir mi? Bu çok mümkün görünmüyor. Ancak tekrar, var olandan bir tane daha yapma düşüncesi zaten Warhol'un kendisi tarafindan 
gerçekleştirilmişti. $\mathrm{Bu}$ doğrultuda bu sanatçıların yinelediklerinin Campbell's Corba Kutularìndan ziyade Warhol'un tavrı olduğunu söylemek daha doğru olacaktır. Çünkü izleyici için hatırlattı̆̆ aslın, o markanın süpermarket reyonundaki yiyecek ürünü olması gerekirdi. Oysa izleyici önce Warhol'un müze ya da galeride sergilenen eserleri ile bağdaşım kuruyorsa ki bu oldukça muhtemel, o zaman onu sanat yapıtı yapan şeyin kullanılan nesne tercihi ile sınırlandırılamadığının da en güzel kanıtıdır. Bu da Warhol'un tam da yapmak istediği şeydir.

Sonuç olarak onun yaklaşımının çok benzerini günümüzde sunuyor olmak o kadar da şaşırtıcı değil. Çünkü o zaten hazır olan ve başkası tarafindan tasarlanmış, herkesin görebileceği ambalajları izleyicinin önüne ilk çıkardığında, her şeyi tüketmeye alışan bir kitle için, sanat ve tüketim birlikteliğini sunmak ilginçti. Ancak kopyanın kopyasını şimdi sunuyor olmak ne kadar ilginç ve şaşırtıcı olur? Ya da Warhol'un tavrı kadar sanat için çığır açıcı mıdır? Ya da Warhol'un Pettibone'nun onun işlerini kopyaladığını gördüğünde değerlendirdiği gibi bunlar gerçekten komik birer kopya mıdır? Yoksa kopyanın kopyası yapılarak Warhol'un tavrı daha da ileri mi götürülmek isteniyor? $\mathrm{Bu}$ denli imge bombardımanına tutulduğumuz çağda kopyaların ve asılların birbirine karışmışlı̆̆ onun kopyaları ile daha etkili mi vurgulanıyor? Hazır nesne ve tüketim malzemesinin sanata sokulma gerekçesi ve mantığı düşünüldüğünde, bu sorulara cevap vermek için sanatın seyrini biraz daha izlemek gerekecektir.

\section{Kaynakça}

Amaral, A. (2001, June): Vik Muniz:Illusionism Beyond Specular Appearance. São Paulo, Vik Muniz Solo Show: Ver para Crer, Modern Sanatlar Müzesi, June 29-Auqust 12, São Paulo, katalog, http://vikmuniz.net/library/vik-muniz-illusionism-beyond-specular-appearance (Erişim tarihi: 12.06 .2018$)$.

Bagley, C. (2008, September 1). Liza Lou. W Magazine. https://www.wmagazine.com/story/liza-lou (Erişim tarihi: 24.06.2018).

Baudrillard, J. (2000). Estetik Yanılsamalar ve Yanılsamabozumlanı. Ş. Demirkol (Çev.) Yapı Kredi Yaymlar: Sanat Dünyamız, 77, s.100.

Danto, A. (2016). Brillo Kutusu:Post-Taribsel Perspektiften Görsel Sanatlar. C. Kayaş (Çev.). İstanbul: Ayrintı Yayınları.

Danto, A.C. (2015). Sanat Nedir. (Z.Baransel Çev.). İstanbul: Sel Yayıncllık.

Feldman Gallery. (1976). Komar\&Melamid, Color is a Mighty Power!, Ronald Feldman Fine Arts Gallery. http://www.feldmangallery.com/media/pdfs/exhk\&m76_press.pdf (Erişim tarihi: 13.11.2015).

Gallery Saint Martin. (Tarihsiz). Mulhem. http://www.galerie-saintmartin.com/artistes/mulhem/?lang=en (Erişim tarihi: 10.06.2018).

Jansen, C. (2013, Auqust 8). Tabaquro Collage: The Importance of a 1920s Cigar Roller rom Havana in the Evolution of Collage Art. Dazed. http://www.dazeddigital.com/artsandculture/article/16844/1/tabaquero-collage (Erişim tarihi: 10.06.2018).

Kalinsky, Y. (tarihsiz). We Buy and Sell Souls-Art Action by Komar\&Melamid and the Nest Group. http://tranzit.org/exhibitionarchive/we-buy-and-sell-souls-art-action-by-komar-melamidand-the-nest-group/ (Erişim tarihi: 13.11.2015).

Leo Castelli Gallery. (2004). Richard Pettibone Sixty-four Campbell's Soup Cans. http://old.likeyou.com/archives/richard_pettibone_castell06.htm (Erişim tarihi: 05.12.2013).

Solti, G. (June). From Means to Ends: Labour As Art Practice (Master of Fine Art). The University of Western, Ontario https://ir.lib.uwo.ca/cgi/viewcontent.cgi?referer=http://beachpackagingdesign.com/boxv ox/oeuvre-overlap-liza-vs-linda\&httpsredir $=1 \&$ article $=3485 \&$ context $=$ etd (Erişim tarihi: 24.06.2018). 
Vitaly Komar and Alexander Melamid (tarihsiz). http://www.rector-associates.com/pdfs/2011Insert-(Komar-and-Melamid).pdf (Erişim tarihi: 13.11.2015).

Walsh, B. (2011, September 15). Jesus Made Pettibone Mock His Idols. Art in America, https://www.artinamericamagazine.com/news-features/news/richard-pettibone-leocastelli-recent-works/ (Erişim tarihi: 10.06.2018).

\section{Resim Listesi}

Resim 1. Andy Warhol, Campbell's Çorba Kutuları II, 1969, https://www.pinterest.ch/pin/35114072073262014/ 12.09.2018.

Resim 2. Felipe Jesús Consalvos, Meraklı Geleneksel Gözlemler, 1920-50, https://www.artsy.net/artwork/ felipe-jesus-consalvos-curious-traditional-observations 10.06.2018. Resim 3. Richard Pettibone, Campbell's Çorba Kutusu, Sebze ve Arpalı Sığır Eti,

https://www.artsy.net/artwork/richard-pettibone-campbells-soup-can-beef-with-vegetables-andbarley 10.06.2018.

Resim 4. Vitaly Komar ve Alexander Melamid,, Post-Art \#1 (A. Warhol), 1973, https://www.saatchigallery.com/artists/vitalykomar_alexandermelamid.htm 12.09.2018.

Resim 5. Mike Bidlo, Warhol Değil (Campbell's Çorba Kutusu, Tavuklu Bamya Çorbası, 1984-86, https://www.saatchigallery.com/artists/mike_bidlo.htm 10.06.2018.

Resim 6. Liza Lou, Campbell's Çorbas1, Domates, 1992,

https://www.artsy.net/artwork/liza-lou-campbells-soup-tomato 10.06.2018.

Resim 7. Vik Muniz, Radyatör Tavuk Erişte (Warhol'dan Sonra), 2007, http://ikonltd.com/past/69/\# 10.06.2018.

Resim 8. Devorah Sperber, Warhol'dan Sonra, 2008, http://www.devorahsperber.com/thread_works_index_html_and_2x2s/warhol_soup_can. htm 10.06.2018.

Resim 9. Mel Ramos, Suzy Çorba Kutusu, 2009, http://www.artnet.com/artists/mel-ramos/suzysoup-a-UONhR0hiBddKc1FZxUvRjg2 12.09.2018.

Resim 10. Lluis Barba, Sanatta Turistler, Jean-François Millet 2009, http:/ /lluisbarba.com/travellers-in-time 10.06.2018.

Resim 11. Magnus Gjoen, Çorba İle İlgili Endişeleri Daha İyi Hale Getirmek, 2012, https://www.magnusgjoenart.com/fullscreen-page/comp-irot3bre/8c78975b-5370-4d18b148-7c2ee2c053ab/41/\%3Fi\%3D41\%26p\%3D\%26s\%3D 12.09.2018.

Resim 12. Gregg Gibbs, Andy Warhol Değil, Biberlik, 2013, https://www.artsy.net/artwork/gregggibbs-not-andy-warhol-pepper-pot-1 10.06.2018.

\section{Resim 13. Dominique Mulhem, Campbell's Mondrian, 2018, https://www.artsper.com/en/contemporary-artworks/print/309724/campbells-mondrian $\underline{10.06 .2018 .}$.}

\section{Extended English Summary}

It is not a new event for a ready object to take part in art. However, Warhol's consumption object is a different process. Soup can declares its presence with the replica. However, this declaration is not in the industry but in art. In Warhol, the originals and the copies are intermingled. Moreover, this is not only repeated by the artist himself. Other artists continue to quote this consumption object. The real question is: Is it the graphic design of an industrial soup can they interpretation? Or is Warhol's attitude? When a copy is repeated, can it be converted to original? Or does it have no intention of being an original because the artwork has already accepted that it is a copy? These questions, which can be further increased, make us think that he has taken a different approach to the idea of reproduction. 
Warhol shows people that they reconcile on consumer goods and artworks or do not deny this way of life. In this sense, we can say that the artists who interpretation the soup cans talk about their lifestyle, the views of the cultures. The commercial object that Warhol uses with his logo is quite familiar to the audience. The logo here brings together the consumer with the art audience on the same platform. Whereas today's soup cans are presented together with their logos, the identity of an artist is in front of that logo. Warhol has almost documented the consumption preferences of American culture pictorial. Like soup cans, coca cola bottles, and well-known people like Marilyn Monroe, Elvis Presley. For the viewer at that time, while these were a part of life, perhaps even if not presently, it can be engaged in a documentary aspect for the viewer after a century. When we look at the repetitions made after that, there is no such thing as Warhol's understanding. However, there is no such thing as a trickery by any of the artists who repeat Warhol. Thanks to the art movements behind each other in Western art, as Danto (2016: 115) has expressed, it is possible to approach the "backward-looking" perspective. Not only value, but the concepts of structure and meaning have also gained new identities. This change is faster when the 20th century comes. The artist has recreated the artistically the past as well as now. In this context, the artist, Warhol, who was the predecessor, became their contemporaries. Repetition becomes more pronounced in the age when art is not going to be a fixed identity and the belief that anything can be a work of art.

Plato refers to the fact that we are transformed into persons or shadows we imitate, and for this reason man must acquire appropriate examples of morality. For example, in Chinese art, Ni Tsan has become a myth or even a command. Ni Tsan collects on the supreme virtues such as purity, courage and calmness in the face of difficulty (Danto, 2016, pp.148-149). The painter who imitates Ni Tsan, at the same time, exhibits a moral attitude and becomes the glory itself. (Danto, 2016, pp.148-149). Perhaps we can say a similar situation for artists who repeat Campbell's Soup Boxes. Warhol has turned a tin can to an artifact to be consumed. He has copied it many times in parallel to this object of consumption. It is likely that it has been selected to repeat with attitude that exhibits against the traditional teachings of the art world. A work of the past is re-established today for different reasons. It is updated with the language of present. Sometimes the artworkrelated theme (such as the war in Guernica) is associated with a war or massacre in our day. The new artwork evokes the past, but at the same time, the historical moment for the viewer is emphasized. However, the artwork that the artists are influenced here is a replica of a commercial product. The artistic understanding of Warhol, linked with popular culture and consumption, can be replicated even in the 21st century. However, Campbell's soup boxes in his glorious attitude did not always have this point of view in subsequent repetitions. When Warhol, soup cans, Brillo boxes were first introduced to art, the popular image was incorporated into art and the consumption object became a work of art. This was a breakthrough innovation at that time. Can the commercial object sanctified by Warhol be sanctified again? Or is it possible to give audiences the influence of the fusion of life and art when it is repeated in the 21 st century? It does not seem very possible. But repetition, the idea of doing another one was already carried out by Warhol himself. It would be more accurate to say that the repetition of these artists is largely the attitude of Warhol from Campbell's Soup Cans. Because, for the viewer, it really must have been the food product in the supermarket department.

As a result, it is not so surprising that it is presently very similar to his approach. Because when he first comes out of the already existing packaging designed by anyone else, it was interesting to present the unity of art and consumption for a mass accustomed to consuming everything. But how interesting and surprising is it to present a copy of the copy now? Or is it revolutionary for art as well as Warhol's attitude? Or are these really funny copies as Warhol consider when he saw Pettibone copying his artworks? Or is it desired that Warhol's attitude be further advanced by making a copy of the copy? In this era of image bombardment, Are the copies and originals mixed together emphasized more effectively with his copies? Considering the reason and rationale for the inclusion of ready-made object and consumables in art, it will follow the course of art a little more to answer these questions. 